\title{
Collaborative Research on Adhesion Strength of Thermal Barrier Coatings in JSMS*
}

\author{
Masakazu OKAZAKI ${ }^{* 1}$, Yasuhiro YAMAZAKI ${ }^{* 2}$, Kouichi NAMBA ${ }^{* 3}$, \\ Kazuhiro OGAWA ${ }^{* 4}$, Motofumi OHKI ${ }^{* 5}$, Kazunari FUJIYAMA ${ }^{* 6}$, \\ Hiroyuki WAKI $^{* 7}$, Masayuki ARAI ${ }^{* 8}$, Masaru SEKIHARA ${ }^{* 9}$, \\ Akihiro ITOH ${ }^{* 10}$, Hirotaka FUKANUMA ${ }^{* 11}$, Naoyuki OHNO*12, \\ Hideaki KANEKO $^{* 13}$ and Masashi KAWAMURA ${ }^{* 14}$ \\ ${ }^{* 1}$ Department of Mechanical Engineering, Nagaoka University of Technology, \\ 1603-1 Kamitomiokamachi, Nagaoka-shi, Niigata 940-2188, Japan \\ E-mail: okazaki@mech.nagaokaut.ac.jp \\ ${ }^{* 2}$ Department of Mechanical and Control Engineering, Niigata Institute of Technology, \\ 1719 Fujihashi, Kashiwazaki, Niigata 945-1195, Japan \\ ${ }^{*}$ Machinery \& Systems Hq., Mitsui Engineering \& Shipbuilding Co., Ltd., \\ 1-1, Tama 3-chome, Tamano-shi, Okayama 706-8651, Japan \\ ${ }^{*}$ Fracture and Reliability Research Institute, Tohoku University \\ 6-6-01, Aoba, Aramaki, Aoba-ku, Sendai 980-8579, Japan \\ ${ }^{* 5}$ Department of Materials Science and Technology, Faculty of Engineering, Niigata University. \\ 8050 Ikarashi 2-no-cho, Nishi-ku, Niigata, 950-2181, Japan \\ ${ }^{*}$ Department of Mechanical Engineering, Faculty of Science and Technology, Meijo University \\ 1-501 Shiogamaguchi, Tempaku-ku, Nagoya 468-8502, Japan \\ ${ }^{* 7}$ Department of Mechanical Engineering, Osaka Electro-Communication University \\ 18-8 Hatsu-cho, Neyagawa-shi, Osaka 572-8530, Japan \\ ${ }^{* 8}$ Materials Science Research Laboratory, Central Research Institute of Electric Power Industry. \\ 2-6-1 Nagasaka, Yokosuka-shi, Kanagawa-ken 240-0196 Japan \\ ${ }^{* 9}$ Materials Research Laboratory, Hitachi, Ltd. \\ 1-1, Saiwai-Cho 3 chome, Hitachi-Shi, 317-8511 \\ ${ }^{* 10}$ Electric Power R\&D Center, Chubu Electric Power Co., Inc. \\ 20-1 Kitasekiyama, Odaka-cho, Midori-ku, Nagoya, 459-8522, Japan \\ ${ }^{* 11}$ Representative Director, Plasma Giken, Co. Ltd \\ 4 -1,Imaichi, Ohazayorii-machi, Ohsato-gun, Saitama 369-1214, Japan \\ ${ }^{* 12}$ Engineering Department, Plasma Giken, Co. Ltd \\ 4 -1,Imaichi, Ohazayorii-machi, Ohsato-gun, Saitama 369-1214, Japan \\ ${ }^{* 13}$ Material \& Strength Laboratory, TAKASAGO Research \& Development Center, Mitsubishi Heavy \\ Industries, Ltd. \\ 2-1-1 Shinhanamaarail-cho, Takasago, Hyogo 676-8686, Japan \\ *14 Material Research Department, Technical Institute, Kawasaki Heavy Industries, Ltd. \\ 1-1 Kawasaki-cho, Akashi, 673-8666, Japan
}

\begin{abstract}
This paper introduces the brief summary of the recent collaboration test results on thermal barrier coatings (TBCs) in the JSMS Subcommittee, which covers the measurements of elastic modulus, tensile strength, residual stress and thermal conductivity of the TBC specimens. Here, the round-robin TBC specimens consisting of $8 \%$ yttria stabilized zirconia, CoNiCrAlY alloy bond coat and Ni-base superalloy were prepared by plasma spraying method. The isothermal exposure and the thermal cycles were applied to the TBC specimens by several conditions at high temperatures, to measure both the residual stress and the remaining adhesion strength of the ceramic top, as well as to characterize the thermally grown oxide at the top coat/bond coat interface. The round-robin test results clearly demonstrated that the adhesion strength was significantly changed by the application of thermal
\end{abstract}


cycles and the isothermal exposure. Of particular important results was found in the remaining adhesion strength that were strongly dependent on the testing method to give the thermal cycles.

Key words: Thermal Barrier Coatings (TBCs), Elastic Modulus, Tensile Strength, Thermal Conductivity, Sintering, Residual Stress, Thermally Grown Oxide (TGO), Adhesion Strength, Isothermal Exposure, Thermal Cycling

\section{Introduction}

Thermally insulating ceramic coatings, known as thermal barrier coatings (TBCs) have been essential technologies to improve the performance and efficiency of advanced gas turbines in service at extremely high temperatures ${ }^{(1-6)}$. The key role of TBCs is, of course, to protect the metal substrate from high temperature oxidation and environmental attack ${ }^{(1-2)}$. In general the TBC system consists of at least three layers; ceramic top coat, bond coat and metal substrate. Each layer plays an their own part. For example, the metallic bond coat (usually either by aluminide coating or MCrAlY alloy coating) aids in the adhesion of the ceramic top coat, and also protects the substrate from hot corrosion and oxidation ${ }^{(2,4)}$.

Nobody doubts that the most critical issue to reduce durability of TBCs is spallation of ceramics top coat. Once this type of damage is realized, hot section components made of superalloy substrate may be overheated, resulting in tragic accidents. Adhesion strength is a measure to express a resistance to spalling of ceramics top coat ${ }^{(7,8)}$, where the strength has been often evaluated by, e.g. the ASTM standard ${ }^{(7)}$. In general the adhesion strength of top coat is not constant, but, it must significantly vary during the service period. On evaluating this type of degradation, the following two factors should be taken into account, since TBCs is composite material system consisting of different types of materials: the first is a thermal stress, which is promoted by the mismatches in thermal expansion coefficient and thermal conductivities between the metal substrate, bond coat and ceramic top coat. The second is an environmental damage promoting at the bond/top coat interface. Thermally grown oxides (TGO) is a representative damage by the latter type of attacks $(9,12-14)$. The interaction between the two factors is also important in some cases ${ }^{(12-14)}$.

The subcommittee, "Superalloys and Coatings" in the Society of Materials Science, Japan (JSMS), has been leading some collaborative projects on these articles in Japan for this decade ${ }^{(10-12)}$. Currently the Phase III activity has been running, where some basic properties of TBCs were evaluated through the round-robin tests. The properties deals with there were (i) mechanical and physical properties of top coat, and (ii) adhesion strength of top coat, and (iii) their changes with by isothermal exposure and thermal cycles. In this paper the outline of these test results is introduced.

\section{Experimental method}

The TBC specimens consisting of three layers; Ni-base superalloy, bond coat and top coat, were prepared as the round-robin test specimen. Here, an 8 wt.\% yttria partially stabilized zirconia (YSZ), METCO 204NS, and a CoNiCrAlY alloy, AMDRY9951, were selected as the top and bond coat materials, respectively. As the substrate, on the other hand, two kinds of Ni-base superalloys, MarM247 and IN738LC, were used. The chemical compositions of the top coat, the bond coat ant the substrate are listed in Table 1.

The TBC specimens were fabricated as follows. After spraying the bond coat alloy by $100 \mu \mathrm{m}$ in thickness on the substrate, the YSZ top coat was overlay coated by $500 \mu \mathrm{m}$ in thickness. These processes were performed and managed by atmospheric plasma spraying at Plasma Giken Co.Ltd.. 
The plate TBC specimen of which substrate was MarM247 of $4 \mathrm{~mm}$ in thickness was used to measure the residual stress and the thermal conductivity. On the other hand, the solid cylindrical type of specimen of which geometries were $20 \mathrm{~mm}$ in diameter and $20 \mathrm{~mm}$ in length, respectively, was used to measure the adhesion strength of ceramic top coat. The specimen geometries are shown in Figure 1. Moreover, the self-standing specimens of top coat were also prepared to measure the mechanical properties, of which details are given in Ref. 11 .

In order to measure the mechanical properties of the top coat; elastic modulus and tensile strength, the self-standing rectangular plate specimen of which geometry was $0.5 \mathrm{~mm}$ (;thickness) $\times 10 \mathrm{~mm}$ (;width) $\times 70 \mathrm{~mm}$ (;length), was prepared according to the following procedures: after coating the top coat on the substrate alloy, the substrate was fully resolved chemically to extract the self-standing specimens. No surface polishing was performed for the specimen. Elastic modulus and tensile strength were measured by applying tensile axial load to the specimen length direction. Here, upon applying the external load both the strain gauges and the steel tabs were adhered on the gauge section center and on the gripping part of specimen, respectively.

Either thermal cycles or isothermal exposure was applied to the TBC specimens, according to the test conditions summarized in Table 2. Here, the isothermal exposure was given by means of electric furnace in air. The thermal cycles were applied, following the two different type of test methods; METHOD I and II. In the "METHOD I" one single furnace was used to heat-up and cool-down the TBC specimen under cycle frequency low enough that temperature in the TBC specimens might be changed in steady state without insignificant temperature distribution (Fig.1). There were two furnaces; higher and lower furnaces, in the "METHOD II" thermal cycle test, where the temperature of the two furnaces were set-up so that they were at higher and lower temperatures in thermal cycles test, and the TBC specimens were reciprocated between the two furnaces. In the "METHOD II, the removing time was so short (i.e., within 30 seconds.) that the temperature gradient in the specimens was significant during the reciprocating period, as documented in Section 3.3. The tests by the "METHOD II" were carried out either in air and in vacuum $\left(\sim 10^{-4} \mathrm{~Pa}\right)$. These thermal cycle test conditions are summarized in Table 2.

After giving either thermal cycles or isothermal exposure, the residual stress in the top coat was measured by the stress relief method. Here the stress was evaluated from the measurement of relief strain between before/after the removal of superalloy substrate. The residual adhesion strength of the top coat was also evaluated, according to the ASTM standard, C633 ${ }^{(7)}$.

Table 1 Chemical compositions (in wt.\%).

(a) Top coating powder.

\begin{tabular}{|c|c|c|c|c|c|c|}
\hline $\mathrm{ZrO}_{2}$ & $\mathrm{Y}_{2} \mathrm{O}_{3}$ & $\mathrm{HfO}_{2}$ & $\mathrm{MgO}$ & $\mathrm{SiO} 2$ & $\mathrm{TiO}_{2}$ & $\mathrm{CaO}$ \\
\hline 90.5 & 7.5 & 1.6 & $<0.01$ & 0.04 & 0.11 & 0.02 \\
\hline
\end{tabular}

(b) Bond coating powder.

\begin{tabular}{|c|c|c|c|c|}
\hline Co & $\mathrm{Ni}$ & $\mathrm{Cr}$ & $\mathrm{Al}$ & $\mathrm{Y}$ \\
\hline 38 & 32 & 21 & 8 & 0.5 \\
\hline
\end{tabular}

(c) Substrate alloys.

\begin{tabular}{|c|c|c|c|c|c|c|c|c|c|c|c|c|}
\hline & $\mathrm{C}$ & $\mathrm{Si}$ & $\mathrm{Mn}$ & $\mathrm{Cr}$ & $\mathrm{Co}$ & $\mathrm{Mo}$ & $\mathrm{W}$ & $\mathrm{Cu}$ & $\mathrm{Ta}$ & $\mathrm{Ti}$ & $\mathrm{Al}$ & $\mathrm{Ni}$ \\
\hline IN738LC & 0.09 & 0.04 & - & 16.0 & 8.14 & 1.65 & 2.58 & - & 1.72 & - & 3.57 & Bal. \\
\hline MarM247 & 0.15 & 0.02 & $<0.01$ & 8.36 & 9.94 & 0.64 & - & $<0.01$ & - & 1.03 & 5.53 & Bal. \\
\hline
\end{tabular}


Table 2 Conditions and procedures for thermal loadings.

\begin{tabular}{|c|c|c|c|c|}
\hline Thermal loading & Environment & $\begin{array}{c}\text { Temperature / } \\
\text { Temperature range }\end{array}$ & $\begin{array}{c}\text { Time / } \\
\text { Number of cycle }\end{array}$ & Institute \\
\hline $\begin{array}{l}\text { High temperature } \\
\text { (isothermal) } \\
\text { exposure }\end{array}$ & in air & $\begin{array}{c}800^{\circ} \mathrm{C}, 900^{\circ} \mathrm{C} \\
1000^{\circ} \mathrm{C}, 1100^{\circ} \mathrm{C}\end{array}$ & $\begin{array}{c}0,100 \mathrm{hrs}, 300 \mathrm{hrs}, \\
1000 \mathrm{hrs}\end{array}$ & $\begin{array}{c}\text { NUT, NIIT, Meijo } \\
\text { Univ., KHI, CRIEPI, } \\
\text { OECU, MHI }\end{array}$ \\
\hline $\begin{array}{l}\text { Thermal cycling } \\
\text { (Method I) }\end{array}$ & in air & $\begin{array}{c}1000-400^{\circ} \mathrm{C}, 1000 \\
-500^{\circ} \mathrm{C}, 900-400^{\circ} \mathrm{C}, \\
900-650^{\circ} \mathrm{C}\end{array}$ & $\begin{array}{c}0,100 \text { cycles, } \\
300 \text { cycles }\end{array}$ & $\begin{array}{c}\text { CRIEPI, Niigata } \\
\text { Univ., NUT, Tohoku }\end{array}$ \\
\hline \multirow{2}{*}{$\begin{array}{l}\text { Thermal cycling } \\
\text { (Method II) }\end{array}$} & in air & $1000-400^{\circ} \mathrm{C}$ & $\begin{array}{c}0,10 \text { cycles, } 300 \text { cycles, } \\
500 \text { cycles, } 1000 \text { cycles }\end{array}$ & NUT \\
\hline & in vacuum & $1000-500^{\circ} \mathrm{C}$ & 0,100 cycles & Niigata Univ. \\
\hline
\end{tabular}

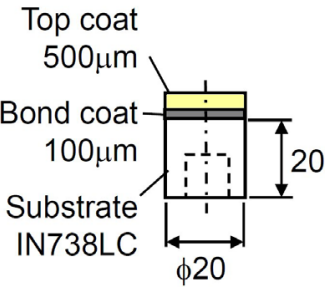

(a) Adhesion test

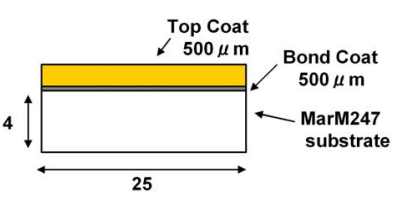

(b) SEM observation and

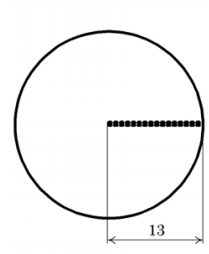

Coatin

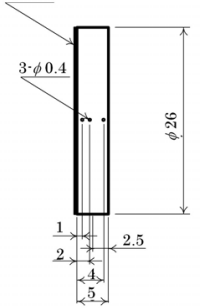

(c) Thermal conductivity measurement

Fig.1 Geometries of specimens used (unit in $\mathrm{mm}$ )

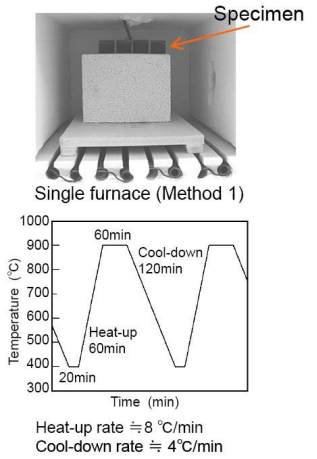

(a) Method 1:

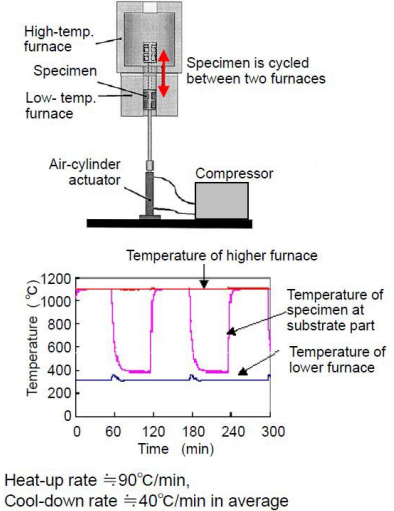

(b1) Method II in air

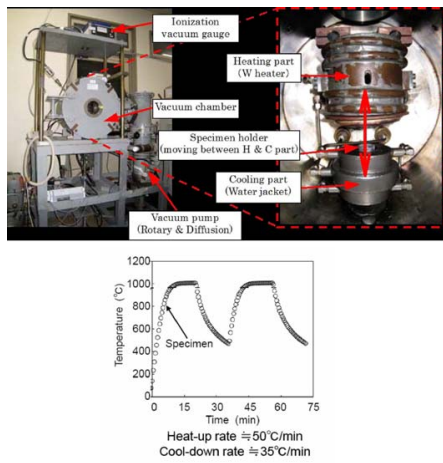

(b2) Method II in vacuum

Fig.2 Test apparatus used for the thermal cycle tests. The temperature history in each is schematically illustrated. More quantitative information will be given in Fig.

\section{Results and discussion}

\subsection{Elastic modulus}

The elastic modulus measurements of the top coat are summarized in Fig.3. Here, the elastic modulus was determined from a slope in stress-strain curve monitored through a strain gauge. It is found from Fig. 3 that the modulus significantly increased when the specimens were exposed at high temperatures for long time. For example, the elastic modulus after exposed at $1000^{\circ} \mathrm{C}$ increased from an initial value of about $20 \mathrm{GPa}$ to about $35 \mathrm{GPa}$ after 1000 hours. When the exposure time was long enough, the modulus seemed to be almost saturated. These increases might be resulted from progress of sintering of the top coat during isothermal exposures. As a matter of fact, a decrease in microporosity fraction with isothermal exposure was observed in the Phase II activities ${ }^{(11)}$. 


\subsection{Tensile strength}

The tensile strength of the top coat was measured using the same specimens as those for the Young's modulus, which was summarized in Fig.4 as a function of high temperature exposure time. The data points in Fig. 4 reveal the average of the measured value using three specimens. The scatter were about $\pm 3 \mathrm{MPa}$, almost $10 \%$ of the absolute value. It is found from Fig. 4 that the tensile strength also increased with thermal exposure time. The change is significant compared with the scatter, while the scatter must be sensitive to the specimen preparation procedure. When the exposure time was long enough, the increase of tensile strength seemed to be converged. It is worthy to note from Figs. 3 and 4 that the increasing behavior in tensile strength is similar to that in elastic modulus, suggesting the both type of changes were caused by the same mechanisms. One of mechanisms must be a sintering.

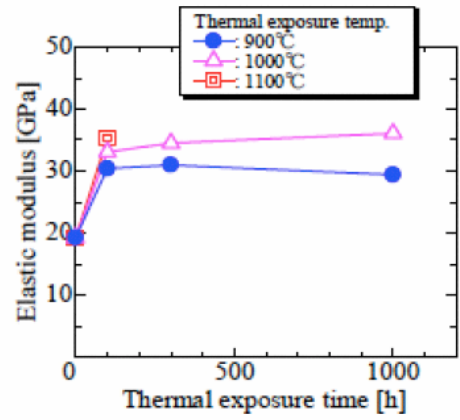

Fig.3 Effect of high temperature exposure on elastic modulus of top coat

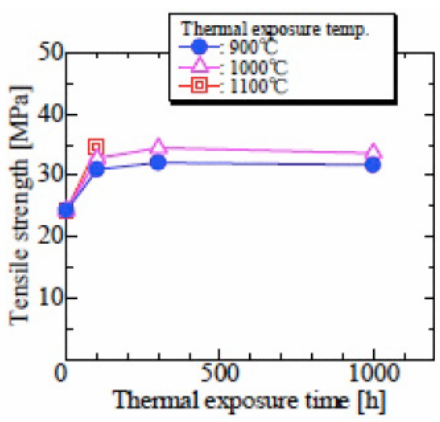

Fig.4 Effect of high temperature exposure on tensile strength of top coat

\subsection{Thermal conductivity of Top coat}

The thermal conductivity of the top coat, $\lambda_{\mathrm{tc}}$, was measured according the laser heat flux rig test method employed elsewhere ${ }^{(12,13)}$. In this work the value of $\lambda_{\text {tc }}$ was approximately calculated from the steady state temperature gradient in the TBC system by,

$$
\lambda_{\mathrm{tc}}=\lambda_{\mathrm{bm}} \frac{\left(T_{\mathrm{i}}-T_{\mathrm{b}}\right) / t_{\mathrm{bm}}}{\left(T_{\mathrm{s}}-T_{\mathrm{i}}\right) / t_{\mathrm{tc}}}
$$

where $\lambda_{\mathrm{bm}}$ is thermal conductivities of the base metal, and $t_{\mathrm{tc}}$ and $t_{\mathrm{bm}}$ are thickness of the top coat and that of base metal including bond coat, respectively. $T_{\mathrm{i}}, T_{\mathrm{b}}$ and $T_{\mathrm{s}}$ are temperatures at the bond/top coat interface, at the bottom of substrate and at the surface of top coat, respectively: those were measured by thermocouples mounted inside or outside of the specimen. The changes of thermal conductivity measured are summarized in Fig. 5. As 


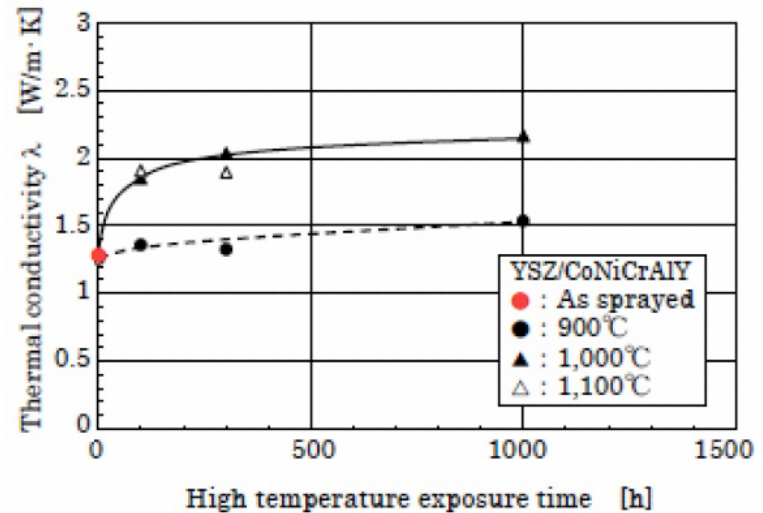

Fig.5 Change of thermal conductivity with high temperature exposure, measured by the steady-state laser heat flux rig test.

shown there, whereas the thermal conductivity rapidly increased at the beginning of exposure, the increasing rates almost converged after a prolonged exposure, depending on the exposing temperature. These behaviors must be also corresponding to progress of sintering.

\subsection{Residual stress}

In this work the residual stress in the ceramic top coat was measured from the relief strain when the substrate was completely dissolved from the TBC specimen ${ }^{(14)}$. The value of residual stress was approximately evaluated by

$$
\sigma_{\mathrm{r}}=\mathrm{E}_{\mathrm{tc}} \varepsilon_{\text {relief }}
$$

where $E_{\mathrm{tc}}$ and $\varepsilon_{\text {relief }}$ are elastic modulus of top coat (Fig.3), and a released strain after complete removal of substrate, respectively. In Eq. (2) the stiffness of substrate is approximated to be high enough, compared with that of top coat. Figure 6 summarizes the residual stress measurement in the top coat. The residual stress on the as-sprayed top coat was almost zero or slightly tensile. After exposed at higher temperature, it varied into compression, corresponding with the typical results reported elsewhere ${ }^{(14)}$.

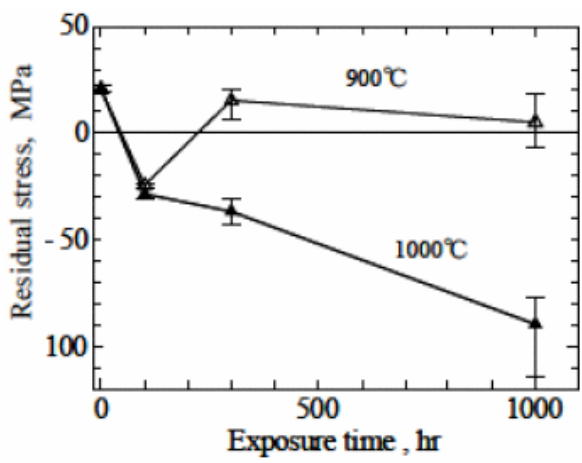

(a) Results obtained by the member $\mathrm{A}$

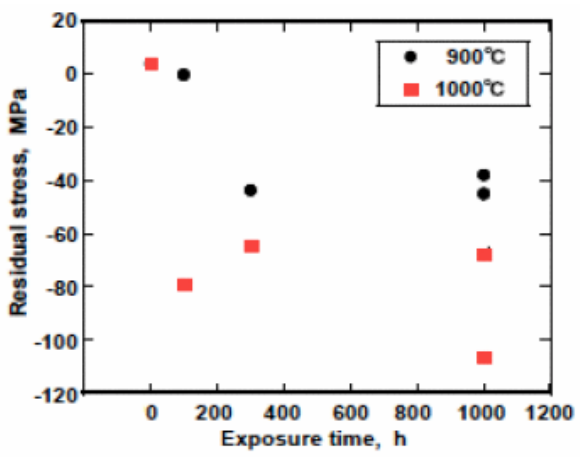

(b) Results obtained by the member B

Fig.6 Relationship between residual stress on the surface of top coat and exposure time

\subsection{TGO growth}

Figures 7 shows the SEM photograph of TGO at the interface between the top coat and bond coat. Whereas alumina was a major component in specimens exposed at $900^{\circ} \mathrm{C}$, a mixed oxide consisting of $\mathrm{Ni}, \mathrm{Co}$ and $\mathrm{Cr}$ were dominant ${ }^{(14)}$. 


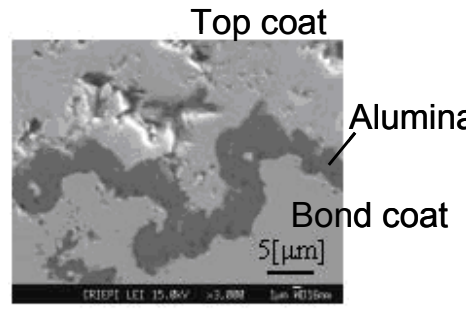

(a) 300 hours at $900^{\circ} \mathrm{C}$

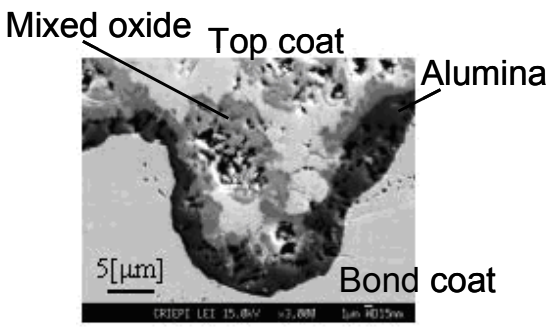

(b) 1000 hours at $1000^{\circ} \mathrm{C}$

Fig.7 SEM observations of TBC exposed at high temperature exposure

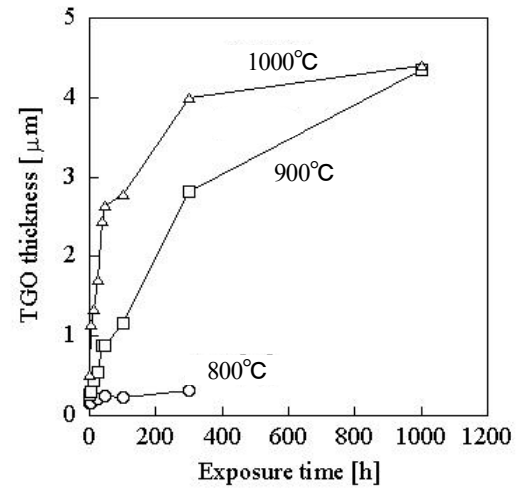

Fig. 8 Growth curve of thermally grown oxide thickness

The TGO thickness was measured on the cross section of the respective TBC specimens (Fig.8). The TGO thickness rapidly increased with increasing of exposure time, depending on the isothermal aging temperature.

\subsection{Adhesion strength}

(1) Change of adhesion strength by isothermal exposure

Figure 9 indicates change of adhesion strength of top coat with isothermal exposure time and temperatures, where the adhesion strength was measured almost according to the ASTM (JIS) standards ${ }^{(7)}$. Note that adhesion strength was significantly increased with high temperature exposures. This result corresponds with ones by other researchers ${ }^{(14-16)}$.

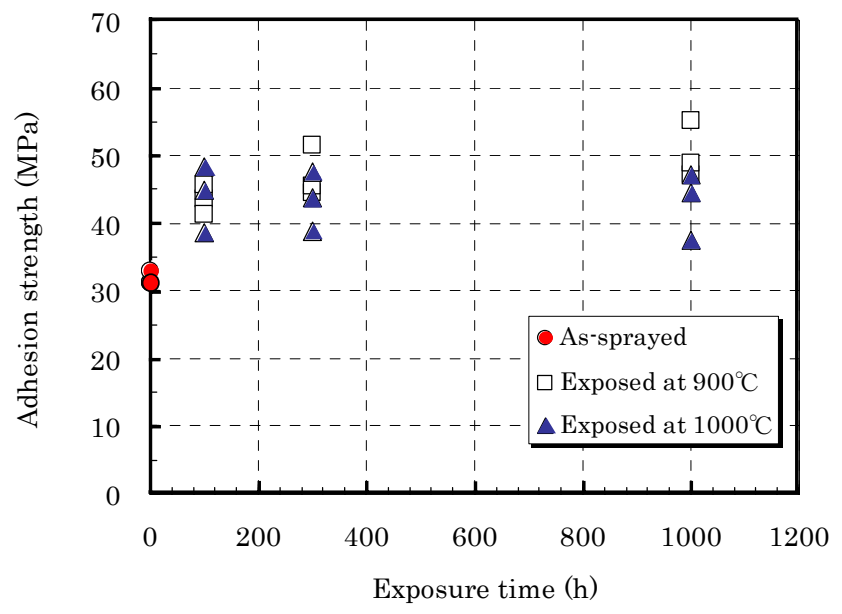

Fig.9 Effect of high temperature exposure on adhesion strength 
Each TBC specimen was cut to observe where the decohesion was taken place. As shown in Fig.10, the fracture occurred almost within the top coat near the interface in as-sprayed specimens. Comparing Fig.10(a) and (b), the fracture area get close to the interface with the progression of isothermal aging. Comparing Fig. 10 with Fig.4, it is natural to postulate that the increase in adhesion strength would be attributed to the increase of top coat strength.

\section{(2) Change of adhesion strength by thermal cycles (by the test Method I)}

The adhesion strength of the top coat in the TBC specimen is given in Fig. 11, where the thermal cycles were given to the specimen by the Method I; see Fig.2. In this test method, thermal stress is supposed to be induced by thermal expansion misfit in the TBC system at nearly steady-state condition. The change of adhesion strength with the thermal cycles is given in Fig.11. It is found that the adhesion strength increased at least up to 300 cycles. This was similar to the test results shown in Fig.9. It is important to note that there was no significant effect of the cycling temperature range. The results of Fig.11 were a little conflicting with those in Refs. ${ }^{(15,16)}$. This would be attributed to such a condition that the numbers of cycles applied were relatively shorter than those in Refs. ${ }^{(15,16)}$.

A typical cross-section after the adhesion test is shown in Fig.12, showing the fracture occurred within the top coat but somewhat far away from the interface.

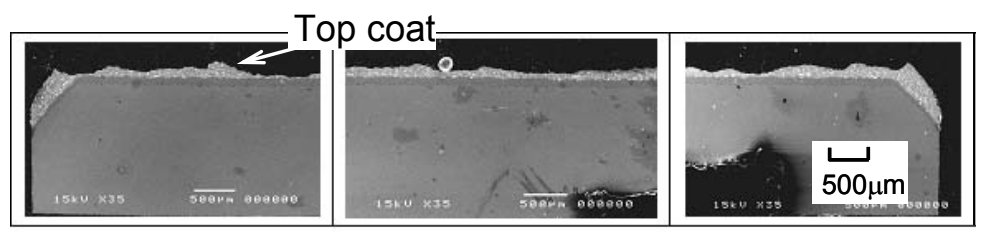

(a) As-sprayed

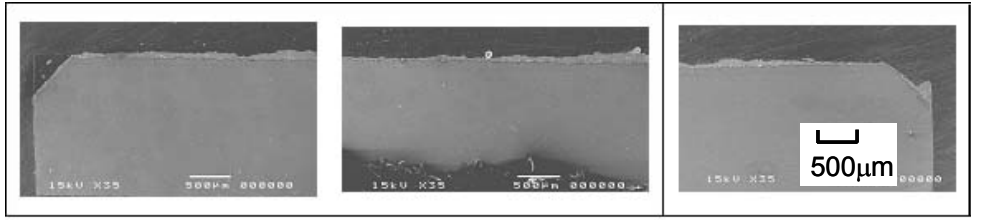

(b) Exposed at $1000^{\circ} \mathrm{C}$ for 1000 hours

Fig. 10 Cross sections of adhesion test failed specimens after exposed at high temperatures

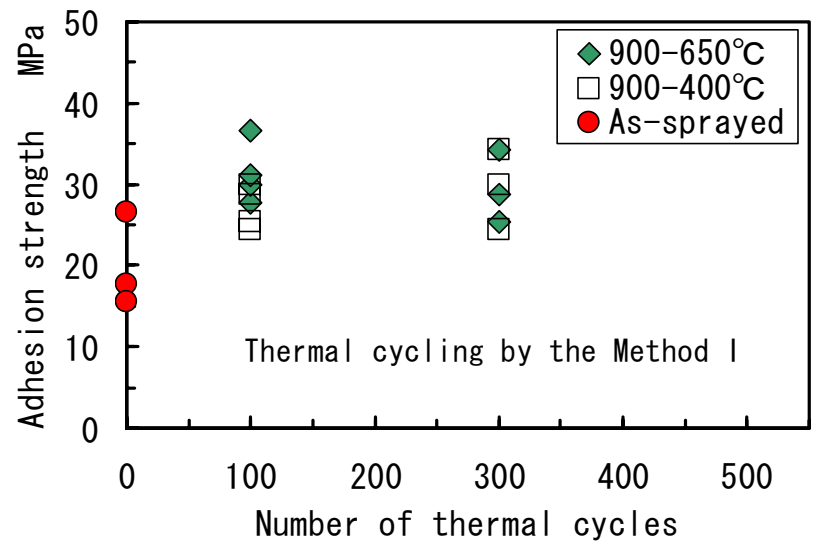

Fig.11 Effect of thermal cycling by the Method I on adhesion strength 




Fig.12 Typical cross section of adhesion test failed specimen after thermally cycled by the Method I

(3) Effect of thermal cycles on adhesion strength (comparison between the test Methods I and II)

The thermal cycling test method following the test Method II has been recently standardized as JIS H $8451^{(17)}$. Figure 13 displays the adhesion strength of the top coat to which thermal cycles were given by the method II in air. In contrast with the result in Fig.11 by the Method I (as well as Figure 16 discussed later), the remaining adhesion strength was obviously decreased by the thermal cycling. However, the decohesion was taken place within the top coat rather than at the interface in this case, as well (Fig.14).

It is worthy to note that there is a significant difference in temperature distribution in the specimen between the Method I and Method II, especially during the transition period in temperature. Figure 15 shows the temperature history in the specimen tested by the Method II in air. This figure clearly shows that the temperature distribution in the specimen was significant during the reciprocating period due to the heat conduction. The thermal stress is, therefore, generated by not only the thermal expansion coefficient mismatch between YSZ top coat and metal substrate but also the non-uniform temperature distribution in specimen. In the Method I, on the other hand, the temperature in the specimen might be almost uniform because the heating and cooling rates were much slow (a heating cycle is approximately $1 \mathrm{~h}$, a cooling cycle is approximately $2 \mathrm{~h}$ ). Such difference of the temperature distribution depending on the thermal cycle test method may lead to the difference between the difference in Figs. 11 and 13. It is important to point out that while the thermal cycle tests seem to be performed without any consideration on the above difference, it may introduce a significant difference in durability of TBCs.



Fig.13 Effect of thermal cycling by the Method II on adhesion strength 


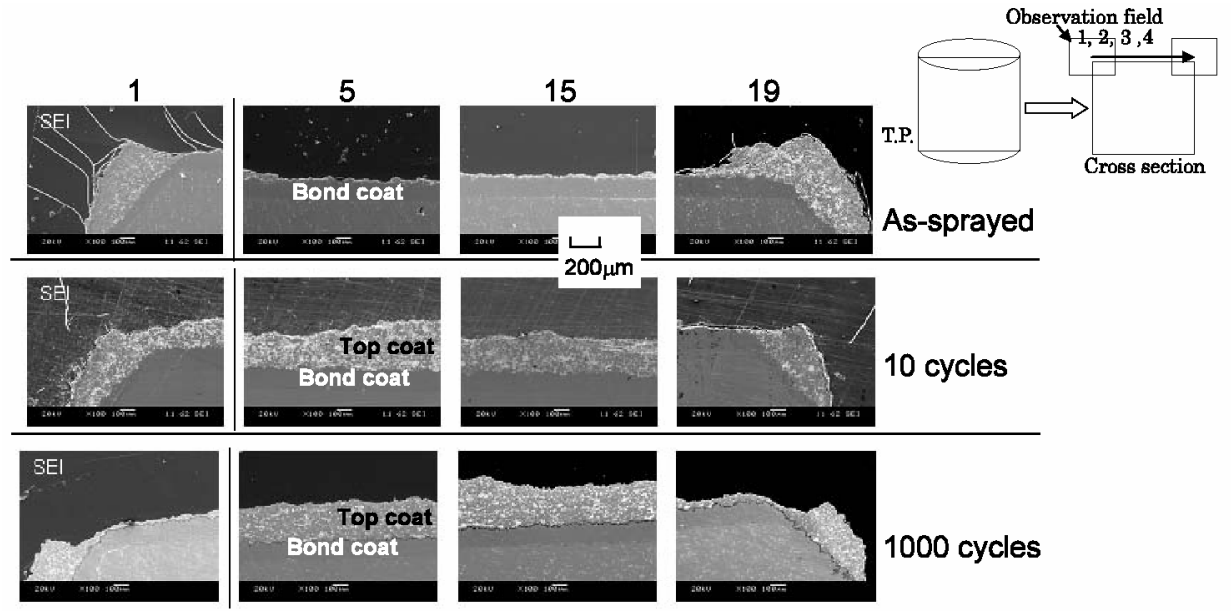

Fig.14 Cross sections of adhesion test failed specimens after thermally cycled by the Method II

\section{(4) Effect of thermal cycles in vacuum}

The thermal cycles were applied to the TBC specimen in vacuum to investigate environmental effect in thermal cycle damage. Here the specimen was subjected to relatively rapid heat-up of $50^{\circ} \mathrm{C} / \mathrm{min}$, followed by holding for 60 minutes at the maximum temperature and then cooled-down by $35^{\circ} \mathrm{C} / \mathrm{min}$ in average. As shown in Fig.16, the adhesion strength increased with thermal cycling in vacuum. Comparing these results with those by the Method I in air in Fig.16, no remarkable effect of environment is found. The TGO growth at the interface was also in significant.

\section{Conclusion}

This paper briefly introduced the recent collaboration test results on the reliability of thermal barrier coatings (TBCs) conducted by the JSMS Subcommittee. Through the round-robin tests, the basic properties of TBCs specimen; elastic modulus, tensile strength,

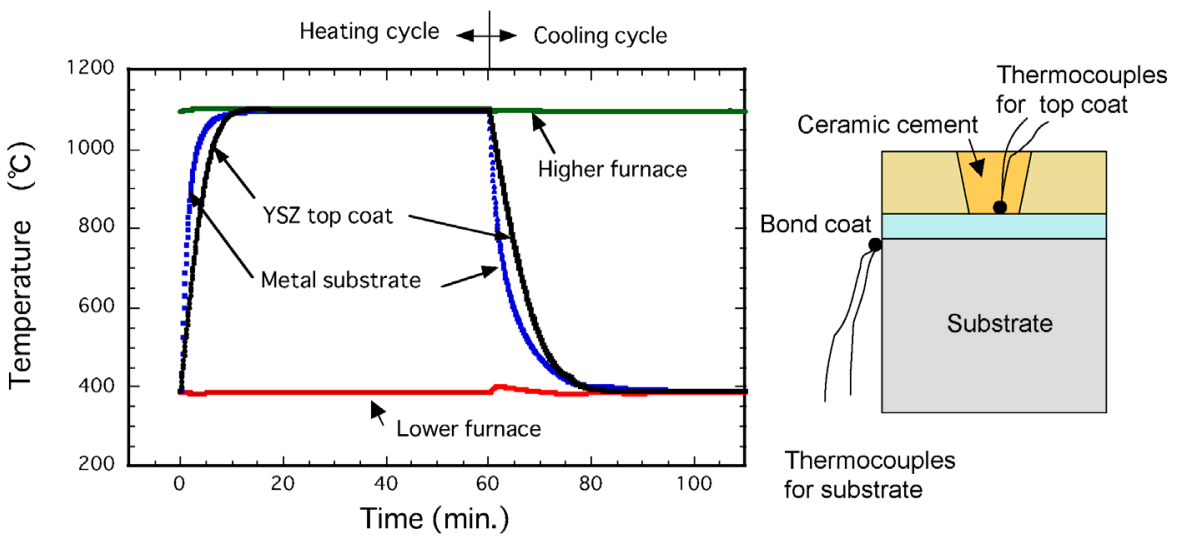

Fig. 15 Temperature history in the specimen tested by the Method II in air (high- and low temperature furnaces method) ${ }^{* 1}$

\footnotetext{
${ }^{{ }^{*} 1}$ In Fig. 15 a more accelerated temperature range than Fig. 13 was repeated to produce an exaggerated condition. Here, the substrate temperature was measured by a thermo-couple at the specimen side near the bond-coat/substrate interface. The top-coat temperature means the temperature in the top-coat near the top-coat/bond-coat interface as shown in Fig.15; a thermo-couple was buried in a grinding hole located at the center of top-coat by the ceramic cement.
} 


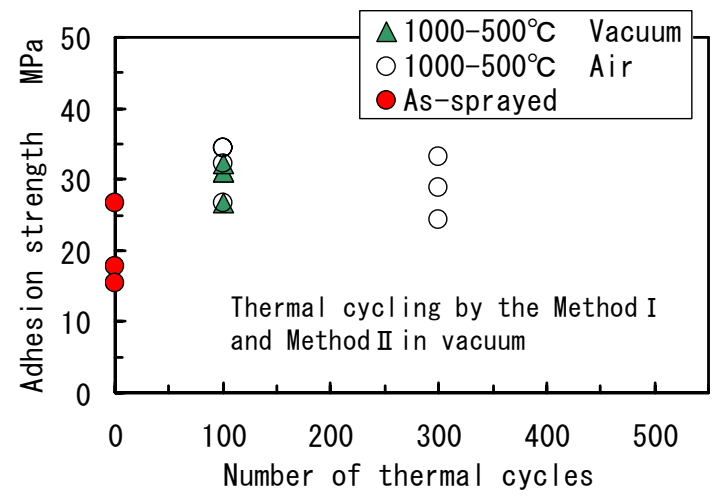

Fig.16 Effect of thermal cycling in vacuum on adhesion strength

residual stress and thermal conductivity of the TBC specimens, as well as their changes, were quantitatively evaluated with the isothermal exposure. The remaining adhesion strength of the ceramic top in the TBC specimen were also evaluated when subjected to the isothermal exposure and the thermal cycles, as well as the characterization of TGO at the interface. It was a new and important finding to understand each other that the effect of testing method to give the thermal cycles on the remaining adhesion strength of the top coat was very significant. This difference was reasonably interpreted by the basic mechanism to induce thermal stress. It is important to point out that the thermal cycles tests seem to be performed without any consideration on the above difference. Reflecting on these findings a next phase activity has started now to get basic understandings on the durability of TBCs under thermo-mechanical loadings.

\section{References}

(1) Miller, R. A., Oxidation Based Model for Thermal Barrier Coating Life, Journal of American Ceramics Society, Vol. 67 (1984), pp. 517-521.

(2) National Research Council, Coatings for high temperature structural materials -Trends and opportunities-, National Academy Press, Washington D.C., (1996).

(3) Seth, B. B., Superalloys:The utility gas turbine perspective, Superalloys 2000, ed. T. Pollock et al., TMS, Warrendale, PA (2000), pp. 3-12.

(4) Schneider, K, and Gruling, H. W., Influence of coatings and hot corrosion on the fatigue behavior of Ni-based superalloys, Thin Solid Films, Vol. 84 (1981), pp. 29-36.

(5) Sudrashan, T. S., (Ed.), Surface Modification Technologies III, TMS, Warrendale, PA, (1990).

(6) Okazaki, M., The Potential for The Improvement of High Performance Thermal Barrier Coatings, Material Research Society International, Vol. 55 (2003), pp. 3-10.

(7) ASTM Standard Test Method for Adhesion or Cohesion Strength of Thermal Spray Coatings, C633. (1999).

(8) Hutchinson, J. W., Metal-Ceramic Interfaces, Ed. by M. Ruhle, A. G. Evans, M. F. Ashby, J. P. Hirth, Pergamon press, London (1990), pp. 295-306.

(9) Rabiei, A, and Evans, A. G., Failure Mechanisms associated with Thermally Grown Oxide in Plasma Sprayed Thermal Barrier Coatings, Acta Materialia, Vol. 48 (2000), pp. 3936-3950.

(10) Okazaki, M., Take, K., Kakehi, K., Yamazaki, Y., Sakane, M., Arai, M., Sakurai, S., Kaneko, H., Harada, Y., Itoh, A., Okuda, T., Nonaka, I., Fujiyama, K., and Nanba, K., Collaborative Research on Thermo-Mechanical and Isothermal Low-Cycle Fatigue Strength of Ni-Base Superalloys and Protective Coatings at Elevated Temperatures in The Society of Materials Science, Japan (JSMS), ASTM STP 1428, (2003), pp.180-194. 
(11) Subcommittee on Superalloys and Coatings, "Phase II Activities", the Society of Materials Science, Japan, (2005). Chaps. 2-5.

(12) D. Zhu and R.A. Miller, Thermal Conductivity and Elastic Modulus Evolution of Thermal Barrier Coatings under High Heat Flux Conditions, NASA/TM-1999-209069 (1999).

(13) Kaneko,H.,Torigoe,T., Reliability Improvement Technology of Thermal Barrier Coating for Industrial Gas Turbines, Proceeding for the 31st Annual Conference of the GTSJ (2003), pp.289-292.

(14) Subcommittee on Superalloys and Coatings, "Phase III Activities", the Society of Materials Science, Japan, (2008). Chaps. 2-5.

(15) Yamazaki, Y., Schmidt, A., and Scholz, A, The determination of the Delamination Resistance in Thermal Barrier Coating System by Four-Point Bending Tests, Surface and Coating Technology, Vol. 201 (2006), pp.744-754.

(16) Arai, M., Sakuma, T., Iwata, U., and Saitou, M., Proposal of Delamination Life Prediction Method of Thermal Barrier Coating Layer under Thermal Cycle Condition, Journal of the Society of Materials Science, Japan, Vol.50, No.6 (2001), pp. 651-656.

(17) JIS H 8451 Testing methods for thermal cycle and thermal shock resistance of thermal barrier coatings, (2007).

\section{Appendix:}

Abbreviated designations of institutes.

NUT: Nagaoka University of Technology

NIIT: Niigata Institute of Technology

Mitsui: Mitsui Engineering \& Shipbuilding Co., Ltd.

Tohoku: Tohoku University

Niigata Univ.: Niigata University

Meijo Univ.: Meijo University

OECU: Osaka Electro-Communication University

CRIEPI: Central Research Institute of Electric Power Industry

Hitachi: Hitachi, Ltd.

Chubu: Chubu Electric Power Co., Inc.

Plasma Giken: Plasma Giken, Co. Ltd.

MHI: Mitsubishi Heavy Industries, Co. Ltd.

KHI: Kawasaki Heavy Industries Co., Ltd. 